\title{
Network Security Assessment Model of Coupling Empowerment
}

\author{
Bin Luo ${ }^{1, a}$, Jingwei Chang ${ }^{2, b}$ \\ ${ }^{1}$ Hebei College of Industry and Technology ,Department of computer technology Shijiazhuang, \\ China \\ ${ }^{2}$ Garden Management Bureau of Chengde city, Chengde, China \\ a'Roject_luo@163.com, b chang_jingwei@sina.cn
}

Keywords: network security; entropy weight; Analytic Hierarchy Process(AHP); fuzzy evaluation; coupling empowerment

\begin{abstract}
By means of accelerating the fuzzy Analytic Hierarchy Process(AHP) screening index of genetic algorithm, this paper constructs evaluation index system of computer network security, puts forward the information entropy with objective and subjective empowerment and improved AHP coupling weighting, sequences the influence factors of network security, the network safety evaluation model is established with the fuzzy comprehensive evaluation method. Application results show that the evaluate results of this model are objective and reasonable.
\end{abstract}

\section{Introduction}

Along with the rapid development of information technology in various fields of economic and social, hackers, computer viruses continuous generation and dissemination, have resulted in significant economic losses to individuals, businesses and countries. How to build a scientific and rational evaluation of network security system, a comprehensive, objective, scientific evaluation of network security situation, is the focus of the protection of information security. Entropy is the important tools of information theory to describe the uncertainty of the information and the random variable, the law of entropy weight is an objective weighting method, its principle is based on the degree of variability of evaluation values reflected in the size of the amount of information to determine the weight of . In this paper, based on a combination of objective and subjective weighting improved Analytic Hierarchy Process (Analytic Hierarchy Process, AHP) with information entropy coupling weighting method to establish a computer network security evaluation model.

\section{The establishment of the network security evaluation model}

\section{Set the index system of evaluation elements.}

In this paper, based on accelerating genetic algorithm fuzzy Analytic Hierarchy Process (Accele-rating Genetic Algorithm Fuzzy AHP, AGA-FAHP) screening, the establishment of evaluation index. The specific approach: ask the experts on the evaluation of the importance of the two indicators for comparison, the establishment of fuzzy complementary judgment matrix $P=\left(p_{i j}\right)$, requiring $0 \leq p_{i j} \leq 1, p_{i j}+p_{j i}=1$ (, shows the extent $\mathrm{i}$ better than $\mathrm{j}$ ). If $\mathrm{P}$ does not have a satisfactory consistency, you need to fix. $\mathrm{N}$ bits can ask experts to independently establish $\mathrm{N}$ rights fuzzy complementary judgment matrix $\mathrm{P}, \mathrm{N}$ group AGA-FAHP solution evaluation in order to improve the reliability of the indicators screening $w_{k, j}(j=1,2, \cdots, M ; k=1,2, \cdots, N)$, the average weight of elected evaluation is $\overline{w_{j}}=\sum_{k=1}^{N} w_{k, j} / N$, the largest $\mathrm{m}$ indicators composed the ultimate computer network security evaluation index system $x_{i}(i=1,2, \cdots, m)$. The evaluation index system obtained by the above screening computer network security is shown in Table 1. 
Table 1. Computer network security evaluation index system

\begin{tabular}{|l|c|}
\hline Primary indicators & Secondary indicators \\
\hline Physical security $B_{1}$ & Line safety $C_{11}$, physical equipment safety $C_{12}$,environmental safety $C_{13}$ \\
\hline Management security $B_{2}$ & Organization systemC $C_{21}$, system construction $C_{22}$, safety training plan $C_{23}$ \\
\hline Software security $B_{3}$ & Operating system security $C_{31}$,application software security $C_{32}$, antivirus software $C_{33}$ \\
\hline Hardware security $B_{4}$ & FirewalC $C_{41}$, intrusion detection system $C_{42}$ \\
\hline Data security $B_{5}$ & Data backup $C_{51}$, access control $C_{52}$, Identity $C_{53}$, data encryption $C_{54}$ \\
\hline
\end{tabular}

\section{The determination of comment set.}

According to the actual needs of the evaluation decision, determine the comment set: $V=\{$ verysafe, safe, safer, basic safe, unsafe $\}$. Assignment to the comment set is $V=\{95,85,75,65,55\}$.

\section{The determination of entropy and the improved coupling weight of AHP.}

Supposing there is $\mathrm{m}$ evaluation index, $\mathrm{n}$ evaluation object, the form of the original data matrix is $X=\left(X_{i j}\right)_{m \times n}$.Entropy weight calculation steps are:(1)Normalization processing the $X$ ' index value, get matrix $X=\left(x_{i j}\right)_{m \times n}$.

(2)Calculated j-th evaluation indicator weight under i-th indicator

$$
p_{i j}=x_{i j} / \sum_{j=1}^{n} x_{i j}
$$

.(3)Calculated i-th indicator entropy: $e_{i}=-k \sum_{j=1} p_{i j} \ln p_{i j}, k=\frac{1}{\ln n}$ empower: $w_{i}=W_{i} w_{i} / \sum_{i=1}^{m} W_{i} w_{i}$.

Coupling weights corrected each evaluation, at the ultimate computer network security evaluation index system indicators.

\section{Fuzzy Comprehensive Evaluation.}

Evaluating each single factor indicators by the evaluation experts (n persons), we can get the single factor membership $\left(n_{1} / n, n_{2} / n, n_{3} / n, n_{4} / n, n_{5} / n,\right)^{n=\sum_{i=1}^{5} n_{i}}$.So, we can get $C_{i}(i=1,2,3,4,5)$.Then, according to the multistage comprehensive evaluation method is obtained in each subset evaluation decision matrix, and finally get the computer network security evaluation result.

\section{An application example}

\section{The determination of index weight at all levels.}

We take the three secondary indicators $\mathrm{C}_{11}, \mathrm{C}_{12}$ and $\mathrm{C}_{13}$ of the primary indicators $\mathrm{B}_{1}$ as example.

(1)Inviting experts make comparison of the three factors of two importance, building the complementary judgement matrix $\mathrm{F}_{\mathrm{C} 1}$, and turning it into fuzzy consistent matrix $\mathrm{F}^{\prime}{ }_{\mathrm{C} 1 \text {, i.e: }}$

$$
F_{C_{1}}=\left(\begin{array}{lll}
0.5 & 1 & 0 \\
0 & 0.5 & 0 \\
1 & 1 & 0.5
\end{array}\right) F_{C_{1}}^{\prime}=\left(\begin{array}{lll}
0.5 & 0.67 & 0.33 \\
0.5 & 0.5 & 0.17 \\
0.67 & 0.83 & 0.5
\end{array}\right), W_{C_{1}}=(0.333,0.213,0.454) \text {. }
$$

(2)To the physical security three evaluation index, invited 10 experts on each index of the important degree to grade raw data matrix:

$$
X_{C_{1}}=\left(\begin{array}{lll}
0.6 & 0.3 & 0.1 \\
0.5 & 0.3 & 0.2 \\
0.4 & 0.4 & 0.2
\end{array}\right) \text {,normalized: } \quad X_{C_{1}}^{\prime}=\left(\begin{array}{ccc}
1 & 0.4 & 0 \\
1 & 0.33 & 0 \\
1 & 1 & 0
\end{array}\right) \text {,entropy weight: }{ }_{C_{1}}=(0.277,0.298,0.225)
$$


(3) Using $w_{i}=W_{i} w_{i} / \sum_{i=1}^{m} W_{i} w_{i}$ on the three evaluation index for correction, get coupling weight vector $\omega_{C_{1}}=(0.358,0.246,0.396)$.Similarly for the others each layer index of the coupling weight, the results such as shown in Table 2.

Table 2. A computer network security evaluation index weight and sort the coupling

\begin{tabular}{|c|c|c|c|c|c|}
\hline $\begin{array}{c}\text { Primary } \\
\text { indicators }\end{array}$ & $\begin{array}{c}\text { Primary } \\
\text { indicators } \\
\text { weight }\end{array}$ & $\begin{array}{c}\text { Secondary } \\
\text { indicators }\end{array}$ & $\begin{array}{c}\text { Secondary } \\
\text { indicators } \\
\text { weight }\end{array}$ & $\begin{array}{c}\text { Combination } \\
\text { weight }\end{array}$ & $\begin{array}{c}\text { Weight } \\
\text { sorting }\end{array}$ \\
\hline Physical & 0.120 & $\mathrm{C}_{11}$ & 0.358 & 0.043 & 10 \\
security $\mathrm{B}_{1}$ & & $\mathrm{C}_{12}$ & 0.246 & 0.030 & 12 \\
\hline Management & 0.097 & $\mathrm{C}_{13}$ & 0.396 & 0.048 & 8 \\
security $\mathrm{B}_{2}$ & & $\mathrm{C}_{21}$ & 0.458 & 0.044 & 9 \\
\hline & $\mathrm{C}_{22}$ & 0.413 & 0.040 & 11 \\
Software & \multirow{2}{*}{0.217} & $\mathrm{C}_{23}$ & 0.129 & 0.013 & 15 \\
security $\mathrm{B}_{3}$ & & $\mathrm{C}_{31}$ & 0.422 & 0.092 & 3 \\
\hline Hardware & 0.353 & $\mathrm{C}_{32}$ & 0.278 & 0.060 & 7 \\
security $\mathrm{B}_{4}$ & & $\mathrm{C}_{33}$ & 0.300 & 0.065 & 6 \\
\hline & & $\mathrm{C}_{41}$ & 0.603 & 0.213 & 1 \\
Data security & \multirow{2}{*}{0.213} & $\mathrm{C}_{42}$ & 0.397 & 0.140 & 2 \\
\hline $\mathrm{B}_{5}$ & & $\mathrm{C}_{51}$, & 0.370 & 0.079 & 4 \\
& $\mathrm{C}_{52}$ & 0.362 & 0.077 & 5 \\
\hline
\end{tabular}

\section{The implementation of the comprehensive evaluation.}

In order to evaluate the safety of the network, we organize the related experts on the secondary index according to the comments concentration of 5 levels to a vote, the normalized results such as shown in Table 3.

Table 3.Experts vote normalization results of a computer network security evaluation secondary indicators

\begin{tabular}{|c|c|c|c|c|c|}
\hline Secondary indicators & Very safe & Safe & Safer & Basically safe & Unsafe \\
\hline $\mathrm{C}_{11}$ & 0.4 & 0.30 & 0.25 & 0.05 & 0.05 \\
$\mathrm{C}_{12}$ & 0.2 & 0.40 & 0.30 & 0.10 & 0.00 \\
$\mathrm{C}_{13}$ & 0.4 & 0.25 & 0.20 & 0.10 & 0.05 \\
\hline $\mathrm{C}_{21}$ & 0.4 & 0.30 & 0.20 & 0.10 & 0.00 \\
$\mathrm{C}_{22}$ & 0.2 & 0.30 & 0.30 & 0.10 & 0.00 \\
$\mathrm{C}_{23}$ & 0.1 & 0.40 & 0.30 & 0.10 & 0.10 \\
\hline $\mathrm{C}_{31}$ & 0.5 & 0.30 & 0.10 & 0.10 & 0.00 \\
$\mathrm{C}_{32}$ & 0.4 & 0.50 & 0.20 & 0.00 & 0.00 \\
$\mathrm{C}_{33}$ & 0.3 & 0.30 & 0.35 & 0.10 & 0.00 \\
\hline $\mathrm{C}_{41}$ & 0.3 & 0.40 & 0.25 & 0.05 & 0.05 \\
$\mathrm{C}_{42}$ & 0.3 & 0.40 & 0.20 & 0.10 & 0.00 \\
\hline $\mathrm{C}_{51}$ & 0.3 & 0.30 & 0.30 & 0.10 & 0.00 \\
$\mathrm{C}_{52}$ & 0.2 & 0.30 & 0.30 & 0.10 & 0.00 \\
$\mathrm{C}_{53}$ & 0.1 & 0.40 & 0.30 & 0.10 & 0.10 \\
$\mathrm{C}_{54}$ & 0.3 & 0.30 & 0.20 & 0.10 & 0.10 \\
\hline
\end{tabular}

So, the first indicators physical security weight vector is:

$$
W_{B_{1}}=W_{C_{1}} \cdot R_{1}=(0.358,0.246,0.396)\left(\begin{array}{lllll}
0.4 & 0.3 & 0.25 & 0.05 & 0.05 \\
0.2 & 0.4 & 0.3 & 0.1 & 0 \\
0.4 & 0.25 & 0.2 & 0.1 & 0.05
\end{array}\right)=(0.396,0.3,0.25,0.1,0.05)
$$

Through normalization: $\bar{W}_{B_{1}}=(0.36,0.27,0.23,0.09,0.05)$.Similarly,

$$
\begin{aligned}
& \bar{W}_{B_{2}}=(0.33,0.25,0.25,0.08,0.08), \bar{W}_{B_{3}}=(0.36,0.27,0.27,0.09,0), \\
& \bar{W}_{B_{4}}=(0.27,0.36,0.23,0.09,0.05), \bar{W}_{B_{5}}=(0.27,0.27,0.27,0.1,0.08)
\end{aligned}
$$


So as to get the computer network security evaluation results of A weight vector:

$W_{A}=W_{B} \cdot R_{B}=W_{B} \cdot\left(\bar{W}_{B_{1}}, \bar{W}_{B_{2}}, \bar{W}_{B_{3}}, \bar{W}_{B_{4}}, \bar{W}_{B_{5}}\right)^{T}=(0.27,0.353,0.23,0.1,0.08)$.

Through normalization: $\bar{W}_{A}=(0.261,0.342,0.223,0.097,0.077)$. Because of $Z=W_{A} \cdot W^{T}$, the network security status for the comprehensive evaluation score is $\mathrm{Z}=81.1$.

Analysis of the results.

Through the calculation above, using the fuzzy comprehensive evaluation method is concluded that the network security evaluation results show that $26.1 \%$ very safe, $34.2 \%$ for security, $22.3 \%$ for a safer, $9.7 \%$ for the basic safety, $7.7 \%$ for safety. According to the principle of maximum membership, the network security rating for the "safe" level, the comprehensive score of 81.1, security is good, the results basically in accord with actual situation.

Table 2 calculation results can be seen: among the influence network security primary factor, hardware safe impact, accounting for 35.3\%; In the secondary factor in primary factor influence, environmental safety, organization system, operating system security, firewall and data backup to the corresponding level factor influences, respectively is $62.5 \%, 45.8 \%, 42.2 \%, 60.3 \%$ and $37.0 \%$; In the secondary factor in computer network security in the overall effect, firewall and intrusion detection system for network security influence row in 15 index the first position, the second, specific gravity are $21.3 \%$ and $14.0 \%$ respectively, therefore, in the network security, it shall pay special attention to hardware security on the influence of computer network security.

\section{Conclusions}

Influence factors of computer network security has multi-level and multi-attribute characteristic, for this reason, this paper puts forward a kind of based on improved AHP and information entropy coupling empowerment computer network security evaluation model. The numerical example shows that, this model can for the network system security strategy and security solutions offer establish the basis, so as to guide the network information system security system and the construction of the management system. Due to the different assessment method to analyze the problem from different angles, and the result also unavoidably exists deficiencies, so to all kinds of evaluation method in combination, innovation, the comparison is the next research direction.

\section{References}

[1] Park J H. Synchronization of Genesio Chaotic System via Back- stepping Approach[J]. Chaos Solitons Fractals, 2006, 27(5): 1369- 1375.

[2] Yan Junjun, Yang Yi-Sung, Chiang Tsung-Ying, et al. Robust Synchronization of Unified Chaotic Systems via Sliding Mode Control[J]. Chaos, Solitons and Fractals, 2007, 34(3): 947-954.

[3] Wang Xingyuan, Song Junmei. Synchronization of the Unified Chaotic System[J]. Nonlinear Analysis-theory Methods \& Appli- cations, 2008, 69(10): 3409-3416.

[4] Mohamed Z, Nejib S, Haitham S. Synchronization of the Unified Chaotic Systems Using a Sliding Mode Controller[J]. Chaos, Solitons and Fractals, 2009, 42(5): 3197-3209.

[5]Yanmei Li, Jingmin Wang, Shuangtao Li. The Fuzzy Neural Network Model of Smart Grid Risk Evaluation Based on Bayes. Journal of Computers. Vol.6,No.1,2011,1:90 97. 